\title{
Enhancement of sewage sludge dewaterability by fungal conditioning with Penicillium simplicissimum NJ12: From bench- to pilot-scale consecutive multi-batch investigations
}

\section{Neng Tao}

Nanjing Agricultural University

Xiu Wu

Nanjing Agricultural University

\section{Feng Zhang}

Nanjing Agricultural University

Zilei Pi

Nanjing Agricultural University

Jiaqi Wen

Nanjing Agricultural University

Di Fang ( $\nabla$ di.fang@njau.edu.cn )

Nanjing Agricultural University

Lixiang Zhou

Nanjing Agricultural University

\section{Research Article}

Keywords: Fungal treatment, Penicillium simplicissimum, Sewage sludge, Dewatering, Stepwise multiple linear regression, Zeta potential, Protein

Posted Date: March 17th, 2021

DOI: https://doi.org/10.21203/rs.3.rs-287531/v1

License: (c) (1) This work is licensed under a Creative Commons Attribution 4.0 International License. Read Full License

Version of Record: A version of this preprint was published at Environmental Science and Pollution Research on June 29th, 2021. See the published version at https://doi.org/10.1007/s11356-021-15170-0. 


\section{Abstract}

Bench- and pilot-scale successive multi-batch trials were conducted to investigate the performance and sustainability of fungal conditioning with Penicillium simplicissimum NJ12 for improving sludge dewatering. The dominant factors affecting the sludge dewaterability improvement by $P$. simplicissimum NJ12 were also identified. Fungal treatment with P. simplicissimum $\mathrm{NJ} 12$ at a volume fraction of $5 \%$ of the inoculum greatly improved the sludge dewaterability. This improvement was characterized by sharp decreases in the specific resistance to filtration from $1.97 \times 10^{13}$ to $3.52 \times 10^{11} \mathrm{~m} / \mathrm{kg}$ and capillary suction time from 32 to $12 \mathrm{~s}$ within 3 days. Stepwise multiple linear regression analysis showed that a marked decrease (58.8\%) in the protein content in slime extracellular polymeric substances and an increase in the zeta potential of the sludge (from -35 to $-10 \mathrm{mV}$ ) were the most important factors that improved the dewaterability of sludge after fungal treatment. Consecutive processes of fungal treatment could be realized by recirculating the fungal-treated sludge with a recycling rate of $1: 2\left(V_{\text {biotreated }}\right.$ sludge $\left./ V_{\text {total sludge }}\right)$. The treatment effectiveness was maintained only over three successive cycles, but replenishment with fresh $P$. simplicissimum NJ12 would be provided periodically at set batch intervals. These findings demonstrate the possibility of $P$. simplicissimum $\mathrm{NJ} 12$-assisted fungal treatment for enhancing sludge dewatering.

\section{Introduction}

Sewage sludge is a byproduct of biological wastewater treatment and consists primarily of microorganisms, extracellular polymeric substances (EPS), organic fibers, and inorganic particles (Christensen et al., 2015). Generally, sludge management consumes $40 \%-60 \%$ of the total operational costs of wastewater treatment plants (Low and Chase, 1999). To reduce sludge handling costs, dewatering is an indispensable process that can greatly reduce the sludge volume, aid in solidification, and improve the calorific value (Wu et al., 2020). Unfortunately, sludge-borne water is difficult to remove because it is tightly bound to highly hydrated EPS and other sludge components through adhesive forces or chemical bonds (Faye et al., 2019; Liu et al., 2016; Neyens et al., 2004; Sheng et al., 2010).

Various physicochemical methods have been applied to improve the sludge dewatering efficiency, including chemical treatment (e.g., acid, ferric chloride, or lime) (Chen et al., 2001; Wang et al., 2019; Zhang et al., 2014), physical treatment (e.g., ultrasound, or microwave) (Appels et al., 2013; Cai et al., 2018; Khanal et al., 2007), and advanced oxidation processes (e.g., Fenton, ozonation, or persulfate activation) (He et al., 2015; Liang et al., 2020; Maqbool et al., 2019; Wei et al., 2020; Zhang et al., 2014). These treatment methods are effective at removing bound (i.e., interstitial or intracellular) water from sludge flocs through the disintegration of sludge EPS and microbial cells (Wu et al., 2020). However, the high cost and potential ecological risks (e.g., toxic chemical use and residues) sometimes limit the practical application of these methods. Therefore, inexpensive and green approaches for sludge dewatering are required. 
A particularly promising option to improve sludge dewaterability is fungal treatment (Molla and Fakhru'lRazi, 2012). This technology mainly utilizes the ability of several fungal species to entrap solids sludge particles and compress them with their filamentous (hyphae) mycelia, which modifies the porosity of the sludge (More et al., 2010). The first report on fungal treatment for enhancing sludge dewaterability was by Alam and Fakhru'I-Razi (2003). They found that waste activated sludge treated with a fungal mixed culture of Aspergillus niger and Penicillium corylophilum exhibited a $98.7 \%$ reduction in the specific resistance to filtration (SRF) (minimum of $1.08 \times 10^{12} \mathrm{~m} / \mathrm{kg}$ ) after 6 days of incubation. Similarly, Murugesan and coworkers (2014) found that treatment of chemically enhanced primary treatment sludge with a pellet-forming fungal strain Penicillium sp. improved the dewaterability with a decrease of the capillary suction time (CST) from 83 to $35 \mathrm{~s}$. After characterizing the EPS content and composition and the sludge microstructure, some researchers have concluded that the enhancement of sludge dewaterability with fungal treatment is highly related to degradation of slime EPS and the formation of larger and stronger bioflocs (Fakhru'I-Razi and Molla, 2007; Liu et al., 2017; Li et al., 2019). Recent investigations have revealed that at specific operating conditions (temperature, agitation, dissolved oxygen, and inoculum concentration) fungal treatment with Penicillium expansum can simultaneously reduce sludge solids (54\% of suspended solids), indicator pathogens (2-4 log cycles of total coliforms and Salmonella), and improve the sludge dewaterability (CST < $20 \mathrm{~s}$ ) (Bala Subramanian et al., 2010). Meanwhile, fungal treatment is less energy consuming because the oxygen supply needs of fungi are approximately one third of the oxygen requirement by bacteria. Fungi also have capability to degrade complex and diverse substrates and grow in adverse conditions (e.g., low temperature) (Chroumpi et al., 2020; More et al., 2010). Because of these excellent performances, fungal treatment is recognized as a cost-effective method for enhancing sludge dewatering and stabilization.

However, most previous studies on the fungus-assisted sludge dewatering have been performed on a bench-scale and for single-batch experiments, and it is not clear whether this process could be scaled up to a pilot-scale, successive multi-batch treatment system using recirculated treated sludge. In particular, little information on the duration or sustainability of fungal treatment for improving sludge dewaterability is available. Furthermore, although previous studies have examined changes in sludge properties (e.g., rheology, surface charge, particle size, and EPS content and composition) during fungal treatment under different laboratory conditions, the most important factors influencing the sludge dewaterability improvement are still not identified, such as using multivariate statistical analysis.

The objectives of the present study were to isolate fungal species with the ability of improving sludge dewatering and investigate the robustness of fungus-assisted dewatering process in bench- and pilotscale consecutive multi-batch systems with recirculated treated sludge. In addition, statistical analysis of stepwise multiple linear regression was used to investigate the relationship between sludge dewaterability and sludge property parameters, and determine the dominant factors affecting the dewaterability improvement of fungal-treated sludge. The outcome of this study will expand our knowledge of the fungal conditioning process and provide information useful for the development of a viable and economical sludge dewatering technology. 


\section{Materials And Methods}

\section{Sewage sludge}

The sewage sludge used in this study was collected from a gravity thickener tank at the Taihu New City Wastewater Treatment Plant in Wuxi, China. All sludge samples were stored at $4^{\circ} \mathrm{C}$. The sludge had a pH of 7.2 , total solids content $2.86 \%$, organic matter content $52 \%$, SRF of $1.97 \times 10^{13} \mathrm{~m} / \mathrm{kg}$, and CST of $32 \mathrm{~s}$.

\section{Isolation and characterization of fungal strain}

Six fungal strains capable of enhancing sludge dewaterability were isolated from sewage sludge by serial dilution technique on Martin rose-bengal agar medium. Among these, the isolate strain NJ12 with the highest ability of decreasing sludge SRF and CST was selected for subsequent sludge treatment experiments. Fungal universal primers (5'-TCCGTAGGTGAACCTGCGG-3' and 5'-

TCCTCCGCTTATTGATATGC-3') were used for PCR amplification in the fungal internal transcribed spacer. The obtained PCR products were sequenced by Shanghai Majorbio Bio-pharm Technology Co., Ltd (China). The resulting sequence was compared with available 18S rDNA sequences in the GenBank database of the National Center for Biotechnology Information (http://blast.ncbi.nlm.nih.gov/Blast.cgi). The phylogenetic tree of the isolate strain NJ12 (GenBank accession number KT207465) was constructed by the neighbor-joining method.

The effect of $\mathrm{pH}$ on the growth of the isolate strain NJ12 was determined in $150 \mathrm{~mL}$ Erlenmeyer flasks, each containing $0.1 \mathrm{~mL}$ active growing culture of the isolate and $50 \mathrm{~mL}$ liquid medium with the different initial $\mathrm{pH}$ values between 1.0 and 8.0. All flasks were incubated on a gyratory shaker at $150 \mathrm{rpm}$ and $28^{\circ} \mathrm{C}$. Fungal growth was determined by the dry mass method after $72 \mathrm{~h}$ of incubation. Four different incubation temperatures ranging from $25^{\circ} \mathrm{C}$ to $40^{\circ} \mathrm{C}$ were selected to examine the effect of temperature on the growth of the isolate strain $\mathrm{NJ} 12$. All experiments were conducted in triplicate.

\section{Preparation of the fungal inoculum}

An inoculum of the isolate strain NJ12 was prepared in the form of mycelial biomass according to the procedures described by Wang et al (2015). First, Czapek-Dox medium was inoculated with fungal cells $\left(\sim 3 \times 10^{6}\right.$ spores $\left./ \mathrm{mL}\right)$ for cultivation of mycelial biomass. After growing in a gyratory shaker at $150 \mathrm{rpm}$ and $28^{\circ} \mathrm{C}$ for 3 days, the fungal culture was collected and filtered through Whatman No. 5 filter paper to remove the residual medium. The mycelial biomass was washed twice with sterilized distilled water and then suspended in sterilized distilled water to its original volume. Mycelial biomass with a dry mass of approximately $6.2 \mathrm{mg} / \mathrm{mL}$ was used as the inoculum for subsequent sludge treatment experiments.

\section{Bench-scale fungal treatment of sludge in batch mode}

To investigate the role of the isolate strain $P$. simplicissimum NJ12 in sludge dewatering and identify the key factors responsible for the dewaterability improvement, four groups of batch experiments of sludge treatment were conducted in 500-mL flasks. Conical flasks, each containing $200 \mathrm{~mL}$ of sludge, were 
inoculated with $P$. simplicissimum NJ12 mycelial biomass at four different volume fractions of: $1 \%, 5 \%$, $10 \%$, and $20 \%$. A flask containing sludge that was not inoculated with $P$. simplicissimum NJ12 was used as a control. All flasks were incubated for 8 days at $150 \mathrm{rpm}$ and $28^{\circ} \mathrm{C}$. All experiments were performed in triplicate.

Sludge samples were withdrawn at regular intervals and analyzed for the $\mathrm{pH}$, zeta potential, SRF, CST, EPS content, and particle size distribution. In addition, organic acid production by $P$. simplicissimum $\mathrm{NJ} 12$ and the cell density of $P$. simplicissimum NJ12 were determined during the fungal treatment process. At the end of the experiment, the microstructural characteristics of the fungal-treated sludge were investigated.

\section{Analytical methods}

The sludge dewaterability (filterability) was evaluated using the CST and SRF (Alam and Fakhru'I-Razi, 2003; Cai et al., 2018), which were measured using a capillary suction timer (304 M, Triton Electronics Ltd., U.K.) and the Buchner funnel test, respectively.

The sludge $\mathrm{pH}$ was measured using a Leici PHS-3C $\mathrm{pH}$ meter. The zeta potential was determined using a Zeta-Plus unit (NanoBrook 90Plus, Brookhaven Instruments, Holtsville, NY). The sludge particle size distribution was measured by laser scattering image analysis (MS2000, Malvern Panalytical). Scanning electron microscopy (S-3400N II, Hitachi Co., Japan) was used to visualize the morphology of the fungaltreated sludge. Slime EPS was obtained according to the extraction procedure described by Wang et al (2015). The sludge was centrifuged at $2500 \times g$ for $15 \mathrm{~min}$ and filtered through $0.45 \mu \mathrm{m}$ membrane. Organic matter in the filtrate was slime EPS. The total organic carbon content was determined using a TOC analyzer (TOC-5000A, Shimadzu). The polysaccharides content in the EPS was determined using the phenol-sulfuric acid method. The proteins content in the EPS was measured using the Lowry-Folin method (Frølund et al., 1996). Quantitative real-time PCR was used to measure the cell density of $P$. simplicissimum $\mathrm{NJ12}$. Production of organic acid was monitored by high performance liquid chromatography with a $\mathrm{C}_{18}$ column (Agilent 1260, Agilent Technologies, CA).

\section{Statistical analysis}

Pearson's correlation analysis was used to evaluate the relationships between sludge dewaterability and sludge properties. Stepwise multiple linear regression (MLR) was used to identify and quantify these relationships. The step criteria used for entry and removal were set according to the significance level of the $F$-value, which was set at 0.05 . Before MLR, min-max normalization was carried out for the sludge properties to prevent attributes with large numerical ranges dominating those with small numerical ranges. In min-max normalization, the minimum value of an attribute was subtracted from each value of the attribute, and then the difference was divided by the range of the attribute. The normalized values were between 0 and 1 . The advantage of this normalization is that it preserves all relationships in the data exactly and does not introduce potential bias. 
MLR was used to develop an equation linking dewaterability to sludge properties. Stepwise MLR constructs a multivariate model for the dependent variable, $Y$, from a few deliberately selected explanatory variables. The best equation is selected according to the highest multiple correlation coefficient $\left(r^{2}\right)$ and takes the following form:

$$
Y=b_{0}+b_{1} X_{1}+b_{2} X_{2}+\cdots+b_{n} X_{n}
$$

where $Y$ is the dependent variable (i.e., the SRF); $X_{1}, X_{2}, \ldots, X_{n}$ are the independent variables (i.e., sludge $\mathrm{pH}$, zeta potential, median particle size $\left(d_{50}\right)$, EPS content and composition, organic acid concentration, and fungal cell density); $b_{0}$ is a constant given by the point where the regression line intercepts the $Y$ axis, which represents the value of $Y$ when all the explanatory variables are 0 ; and $b i(1 \leq i \leq n)$ is the standard partial regression coefficient, representing the amount that $Y$ changes by when the explanatory variable changes by one unit. Equation 1 is a model of the system under investigation in this study and can be used to identify the variables that affect the response and to what extent, and/or to predict the value of one variable when the others are not known.

All statistical analyses were conducted using SPSS Base 18.0 (SPSS Inc., USA).

\section{Pilot-scale fungal treatment of sludge in successive multi-batch mode}

To verify the findings from bench-scale experiments, a pilot-scale treatment system at the Taihu New City Wastewater Treatment Plant was operated in multi-batch mode using recirculated treated sludge. The pilot system consisted of an adjusting tank, a 200-L fungal treatment reactor, a feeding tank, and a diaphragm filter press (Fig. 1). This upscaling of the operation enabled us to evaluate the reproducibility of the fungal treatment process.

First, 7.5 L of $P$. simplicissimum $\mathrm{NJ} 12$ inoculum for fungal treatment was added to the reactor, which contained $150 \mathrm{~L}$ of raw sludge. This experiment ended when the SRF of the treated sludge decreased to approximately $10^{11} \mathrm{~m} / \mathrm{kg}$, and the multi-batch experiment was started. Six consecutive batches of fungal treatment were performed with a sludge recycling rate of $1: 2\left(V_{\text {biotreated sludge }} / V_{\text {total sludge }}\right)$ (Fig. S1). Batches I-VI were conducted using $75 \mathrm{~L}$ of recirculated fungal-treated sludge (i.e., inoculums) and $75 \mathrm{~L}$ of fresh raw sludge. The experiments were not temperature controlled and the temperature range was $20^{\circ} \mathrm{C}-25^{\circ} \mathrm{C}$. After completion of all the batch tests, treated sludge was pumped into a feeding tank using a screw pump and then fed into the diaphragm filter press (Langxun Water Utilities Ltd., Hangzhou, China) for mechanical dewatering. The dewatering process consisted of a 30-min feeding pressing phase with a pressure of $0.6 \mathrm{MPa}$ and a 15-min diaphragm pressing phase with a pressure of $0.8 \mathrm{MPa}$.

\section{Results And Discussion}

\section{Identification of the isolated fungal strain NJ12}


The isolate strain NJ12 was identified as Penicillium simplicissimum by morphological observation (Fig. 2) and molecular characterization (Fig. 3). The P. simplicissimum NJ12 produced clumps of mycelial biomass during its growth. It grew well between $\mathrm{pH} 2.0$ and 7.0, with an optimum $\mathrm{pH}$ range of 3.0-6.0, and had an optimum temperature range of $25^{\circ} \mathrm{C}-30^{\circ} \mathrm{C}$ (Fig. S2). Penicillium is the commonly occurring fungus in municipal wastewater sludge. Fakhru'l-Razi et al. (2002) isolated a total of 70 fungal strains from wastewater and sewage sludge, 39 of which belonged to the genera of Penicillium. Comparative analysis by Kacprzak et al. (2005) showed quantitatively that the genus Penicillium occupied about $50 \%$ of all studied fungal communities dwelling in sludge (with $10^{4}-10^{5}$ colony forming units $/ \mathrm{g}$ of dry solids). Bala Subramanian et al. (2008) isolated the floc-forming fungal strain Penicillium expansum BS30 from wastewater sludge, and found that its filaments could aggregate small particles and reduce the turbidity of effluent during sludge settling under controlled conditions (temperature, agitation, and inoculum dose).

\section{Bench-scale fungal treatment of sludge with $P$. simplicissimum NJ12 in batch mode}

\section{Changes in sludge dewaterability during fungal treatment}

The CST and SRF are widely used to represent the ease of separating water from sludge solids. Generally, sludge with relatively high CST and SRF values (e.g., CST $>20$ s or SRF $>10^{13} \mathrm{~m} / \mathrm{kg}$ ) is difficult to dewater (Cai et al., 2018; Li et al., 2019; Neyens et al., 2004). Variations in the sludge SRF and CST during the fungal treatment process using $P$. simplicissimum $\mathrm{NJ} 12$ with different inoculum percentages are shown in Fig. 4. The results indicated that an optimal dose of fungal inoculum is important for effective dewatering of sludge. For example, good dewaterability was observed in the treatment system with an inoculum volume fraction of $5 \%$, which gave marked decreases in the sludge SRF from $1.97 \times 10^{13}$ to $3.52 \times 10^{11} \mathrm{~m} / \mathrm{kg}$ and the CST from 32 to $12 \mathrm{~s}$ after 3 days of incubation. These values are equivalent to normalized reduction rates of $98.2 \%$ for the SRF and $62.5 \%$ for the CST. Fakhru'l-Razi and Molla (2007) reported that the maximum percentage reduction in sludge SRF was $70 \%$ after 6 days of fungal treatment with Mucor hiemalis. In addition, $57.3 \%$ of reduction in the CST was recorded after sludge was treated with $5 \%$ of Penicillium sp. ACS3 for 4 days (Murugesan et al., 2014). Therefore, P. simplicissimum NJ12 used in this study is comparable to those previously isolated fungi in improving sludge dewaterability.

Meanwhile, it should be noted that inoculation with excessive fungi (e.g., inoculum volume fraction of $20 \%$ ) negatively affected the sludge dewaterability, which resulted in CST and SRF values that were higher than those of the control (without inoculation) over the whole incubation period. This observation is consistent with earlier studies (Molla and Fakhru'I-Razi, 2012; Wang et al., 2015). Some researchers have attributed this deterioration in sludge dewaterability with a high inoculation dose to excessive growth of filamentous fungi. Bala Subramanian et al. (2010) demonstrated that growth of filaments in large quantities ( 10 $\mu \mathrm{m}$ filaments/g of activated sludge) hinders sludge settling, which could be attributed to the fact that excess filaments would physically interfere with close packing of sludge flocs. Whereas, other investigators believed that the growth of fungi in sludge might be restricted because of 
substrate limitation when employing too high inoculum doses, which leads to the failure of fungal treatment (Liu et al., 2017; More et al., 2010).

\section{Changes in sludge $\mathrm{pH}$, surface charge and floc size during fungal treatment}

During the fungal treatment process, the sludge $\mathrm{pH}$, surface charge, and floc size varied greatly as the incubation time increased (Fig. 5). The sludge pH of the treatment system inoculated with $5 \% P$. simplicissimum NJ12 dropped rapidly from an initial value of 7.2 to 5.5 in the first 3 days, and then leveled out at pH 5.0 at day 6 (Fig. 5a). It has been reported that fungi can secrete certain types of organic acids, e.g., oxalic acid, citric acid, and malic acid, by metabolizing wide spectrum of organic substances, depending upon the nature and physiology of the fungus used (Chroumpi et al., 2020; Jernejc and Legiša, 2004). In this study, the dominant organic acid produced by P. simplicissimum NJ12 was gluconic acid with a maximum yield of $45 \mathrm{mM}$. This fungal production of gluconic acid did not result in significant acidification of the treated sludge, possibly because of the strong buffering capacity of the sludge. In fact, from the perspective of subsequent recycling or disposal of the dewatered sludge cake, fungaltreated sludge with a mildly acidic $\mathrm{pH}$ compares advantageously with chemically-treated sludge. It is wellknown that the $\mathrm{pH}$ of sludge treated with persulfate and Fenton's reagent tends to be very low (usually 2.5-3.5) (Liu et al., 2016; Maqbool et al., 2019; Neyens et al., 2004) and this sludge must be neutralized by alkaline additives (e.g., $\mathrm{Ca}(\mathrm{OH})_{2}$ ), which substantially increases the inorganic content of the final sludge cake and largely limits its use in composting, incineration, or land application as a soil amendment (He et al., 2015; Li et al., 2019; Wu et al., 2020). A similar sludge acidification dynamic in both the control group and the fungal treatment group implied that sludge $\mathrm{pH}$ was probably not the key contributing factor to the enhancement of sludge dewaterability observed in this study. This assumption was verified by our subsequent stepwise multiple linear regression analysis.

Surface charge determines the colloid stability of sludge flocs and is an important factor affecting dewatering (Yu et al., 2008). Following inoculation with 5\% P. simplicissimum NJ12, the zeta potential of the sludge rapidly increased from $-35 \mathrm{mV}$ for raw sludge to $-10 \mathrm{mV}$ in the first 3 days, indicating a decrease in the net surface charge on the flocs. In the control without $P$. simplicissimum $\mathrm{NJ} 12$, the zeta potential of the sludge increased to $-22 \mathrm{mV}$ at day 3 and then remained constant throughout the remaining experimental period (Fig. 5b). It is widely accepted that sludge flocs are held together firmly by DLVO forces (i.e., van der Waals and electrostatic forces), non-DLVO forces (i.e., bridging and hydrophobic forces), and physical entanglement (Christensen et al., 2015; Sheng et al., 2010). Because both sludge particles and fungal biomass carried negative charges (e.g., carboxylate and phosphate groups) and they are electrostatically repulsive, the observed interactions between them most likely result from physical entanglement of the mycelia or mycelial EPS, creating favorable conditions for destabilization and flocculation of the colloidal sludge.

Figure 6 illustrates the sludge morphology before and after fungal treatment. The raw sludge existed as rough and fluffy flocs with a discontinuous and porous structure. By contrast, after treatment with $P$. simplicissimum $\mathrm{NJ} 12$, the sludge appeared smooth and compact with a relatively small particle size. 
Many slender mycelia were twined around the sludge particles and filled the spaces between them, which would contribute to the strength and rigidity of the fungal-treated sludge and make it capable of maintaining high permeability under pressure filtration and provide spaces for outflow of free water. Similar phenomena were observed by previous researchers, who ascribed them to the formation of sludge pellets by the physical extrusion and entrapping of the filamentous body (Alam and Fakhru'l-Razi, 2003; Guibaud et al., 2005). In addition, after 3 days of treatment with $5 \%$ P. simplicissimum NJ12, a moderate decrease in the $d_{50}$ of the sludge flocs occurred from 29.09 to $22.93 \mu \mathrm{m}$ (Fig. S3; Table S1), and was probably caused by mechanical destruction by fungal mycelia.

\section{Changes in sludge EPS during fungal treatment}

EPS is considered a key factor in the sludge dewatering process (Faye et al., 2019; Neyens et al., 2004; Wu et al., 2020; Zhang et al., 2014). Several fungi can utilize sludge EPS as sources of carbon and energy for metabolic activity (Chroumpi et al., 2020). In preliminary experiments, we found that fungal treatment with $P$. simplicissimum NJ12 resulted in a sharp drop in the slime EPS concentration but had no substantial influence on loosely bound EPS and tightly bound EPS (data not shown). In particular, for the treatment with $5 \%$ inoculum, the slime EPS content was cut in half at day 3 . Slime EPS are located in the outermost layer of the sludge and weakly bound to the cell surface (Sheng et al., 2010; Wang et al., 2015). Compared with tightly bound EPS and loosely bound EPS, which are located more towards the inner layer, slime EPS perhaps has more opportunities to be metabolized/degraded by P. simplicissimum NJ12.

Further analysis of the major components of the EPS allowed us to determine the compositions that were more likely to be decomposed by P. simplicissimum NJ12. As much as $58.8 \%$ of the protein in slime EPS was decomposed within 3 days and the concentration decreased from 34.5 to $14.2 \mathrm{mg} / \mathrm{L}$, whereas only $28.5 \%$ of the polysaccharide in slime EPS was degraded (Fig. 7). In the control group, both the protein and polysaccharide contents in the EPS were nearly unchanged throughout the whole experiment. This observation supports the idea that a decreased protein content in the sludge EPS could enhance sludge dewatering because of the high water-holding capacity of protein (Cai et al., 2018).

\section{Dominant factors influencing sludge dewaterability during fungal treatment}

Pearson's correlation analysis was used to describe the relationship between the sludge SRF and selected sludge properties ( $\mathrm{pH}$, zeta potential, particle size, cell density, EPS content and composition). A strong negative correlation was found between the SRF and zeta potential $(R=-0.929, p<0.01)$ (Table 1$)$. It has been proven an increase in the zeta potential can result in protonation of negatively charged functional groups in the sludge and thus reduce electrostatic repulsion and reagglomeration of sludge particles and enhance sludge filterability (Faye et al., 2019; Liu et al., 2016; Zhang et al., 2016). In the present study, the sludge $\mathrm{pH}, d_{50}$, and protein and polysaccharide contents in slime EPS were all positively correlated with the sludge SRF. These findings are consistent with those reported by other authors. For example, Xiao et al. (2016) characterized key organic compounds in 20 different types of sludge EPS samples using size-exclusion chromatography combined with organic carbon and organic 
nitrogen detection. They concluded that increases in the contents of low-molecular-weight proteins $(<20$ $\mathrm{kDa}$ ) and monooligosaccharides, alcohols, aldehydes, and ketones ( $<350 \mathrm{Da})$ in EPS were the main contributors to deterioration of the sludge dewaterability. In this study, the correlation coefficients for the seven tested sludge properties were in the order zeta potential $>\mathrm{pH}>$ polysaccharide $>d_{50}>$ slime EPS $>$ protein> fungal cell density, which showed that the zeta potential and sludge SRF were more closely correlated than the other properties.

Correlation analysis conducted with a single parameter could be insufficient because parameters are often interrelated. Consequently, we used a MLR model to quantify the relationship between the sludge SRF and sludge property parameters. After min-max normalization, the following MLR equation was derived for this relationship:

SRF $=-19.93+20.8 \mathrm{pH}-10.7$ zeta potential $-9.88 \mathrm{~d}_{50}-0.08$ cell density -4.3 protein

+0.81 polysaccharide +1.79 slime EPS $\quad R^{2}=0.89 ; P<0.05$

where $R^{2}$ is determination coefficient, and $P$ is the probability for statistical significance.

Analysis of variance was used to determine the significance of the MLR model and the estimated parameters. A determination coefficient $R^{2}$ of 0.89 indicated good agreement between the experimental and modeled results (Eq. 2), but the $p$ values for several estimated parameters were insignificant at the 95\% confidence level $(p>0.05)$ (Table 2). ( $\mathrm{Pr}>\square \mathrm{t} \square$ indicates the $p$-value is a two-tailed probability computed using the $t$ distribution). Therefore, to better describe the relationship between sludge SRF and the above-mentioned sludge properties, the MLR model Eq. 2 was further modified using a step-wise selection scheme. After removing non-significant variables (i.e., pH, cell density, polysaccharide, and slime EPS), a numerical model Eq. 3 was finally established. A determination coefficient $R^{2}$ of 0.907 was achieved with this equation, and the $p$-values of all estimated parameters were significant at the $95 \%$ confidence level $(p<0.001)$.

With stepwise MLR, the most important factors determining the sludge dewaterability improvement during fungal treatment with $P$. simplicissimum $\mathrm{NJ} 12$ were the zeta potential and protein content in slime EPS. It should be pointed out that sludge is very diverse in terms of type and source and its composition is very complex, which makes it difficult to identify all factors affecting sludge dewatering (More et al., 2010; Wu et al., 2020). We believe that other factors could also contribute to sludge dewatering and that further work is needed to verify or recalibrate this model using different types of sludge, such as primary and secondary sludge, waste activated sludge, and anaerobic digested sludge.

\section{Pilot-scale fungal treatment of sludge by $P$. simplicissimum NJ12 in consecutive multi-batch mode}

Good performance at the bench-scale does not guarantee similar efficiency on a larger scale because most of bench studies are performed in the shake flasks, which allows for careful control of important process parameters and avoidance of fluctuations. To better assess the feasibility of fungal treatment for 
engineering application, we constructed a pilot-scale operation system for sludge dewatering. In this trial, six successive batches of fungal treatment were conducted by recirculating the treated sludge rich in $P$. simplicissimum $\mathrm{NJ} 12$ at a recycling rate of $1: 2\left(V_{\text {biotreated sludge }} / V_{\text {total sludge }}\right)$ into the next batch treatment as the inoculum. The pilot-scale operation results (Fig. 8) showed that recirculation of the treated sludge was a feasible method for fungal treatment of consecutive batches. In batch I-III, the sludge SRF decreased by nearly the same rate to a final value of approximately $1.5 \times 10^{12} \mathrm{~m} / \mathrm{kg}$. However, in batch IV, the sludge dewaterability became poor with an elevated SRF value $\left(\sim 4.2 \times 10^{12} \mathrm{~m} / \mathrm{kg}\right)$. This could be linked to nutrient competition from autochthonous microorganisms in the sludge (Kacprzak et al., 2005; More et al., 2010). Interestingly, the sludge dewaterability improved again in batch $\mathrm{V}$ when the reactor was re-inoculated with fresh $P$. simplicissimum NJ12. These results indicate that $P$. simplicissimum NJ12 should be replenished periodically at a set batch interval to maintain the activity of Penicillium species in the sludge and ensure the effectiveness of fungal treatment is sustained.

On the other hand, it was observed that the moisture content of the sludge treated by $P$. simplicissimum NJ12 decreased to $\sim 58.6 \%$ after pressing in a diaphragm filter press. This water content meets the Chinese Discharge Standard of Pollutants for Municipal Wastewater Treatment Plant (GB18918-2008). Moreover, such fungal-treated dewatered sludge cakes can be relatively easily used in composting or incineration because of their high organic matter content and low water content. Further studies on the possibility of different fungi combinations (mixed fungi species) and combinations of fungi with other types of microorganisms (phage, bacteria, and yeasts) to achieve maximum sludge dewatering, solids degradation, and pathogen/toxic compound removal are still needed. Furthermore, a detailed economic evaluation of the fungus-assisted sludge treatment process should be conducted taking into consideration the costs of microbial screening, energy demand, and reactor construction.

\section{Conclusions}

Both bench- and pilot-scale successive multi-batch investigations indicated that $P$. simplicissimum NJ12assisted fungal treatment was technically effective at improving sludge dewatering. Consecutive operations of fungal treatment could be realized by recirculating the fungal-treated sludge and periodically re-adding fresh $P$. simplicissimum $N$ J12. On the basis of statistical analysis by stepwise multiple linear regression, the degradation of protein in slime EPS and the increase in zeta potential were the most important factors affecting the dewaterability improvement of the fungal-treated sludge.

\section{Declarations}

Ethical approval and consent to participate: Not applicable Consent for publication: Not applicable

Availability of data and materials: All data generated or analyzed during this study are included in this published article 
Competing interests: The authors declare that they have no competing interests

Funding: This work was financially supported by National Natural Science Foundation of China (No. 21677077), and the Program for Student Innovation through Research and Training (No. 202010307038Z).

Authors' contributions: Conceptualization: N.T., D.F., and L.X.Z.; Methodology: N.T., and D.F.; Investigation: N.T., X.W., F.Z., Z.L.P., and J.Q.W.; Data curation: N.T., X.W., F.Z., Z.L.P., and J.Q.W.; Writing the original draft: N.T.; Supervision: D.F.; Reviewing and editing: D.F., and L.X.Z. All authors read and approved the final manuscript.

Acknowledgment: We thank the editor and reviewers for their valuable and constructive comments and suggestions.

\section{References}

1. Alam MZ, Fakhru'l-Razi A (2003) Enhanced settleability and dewaterability of fungal treated domestic wastewater sludge by liquid state bioconversion process. Water Res 37:1118-1124

2. Appels L, Houtmeyers S, Degrève J, Van Impe J, Dewil R (2013) Influence of microwave pre-treatment on sludge solubilization and pilot scale semicontinuous anaerobic digestion. Bioresour Technol 128:598-603

3. Bala Subramanian S, Yan S, Tyagi RD, Surampalli RY (2008) A new, pellet-forming fungal strain: its isolation, molecular identification, and performance for simultaneous sludge-solids reduction, flocculation, and dewatering. Water Environ Res 80:840-852

4. Bala Subramanian S, Yan S, Tyagi RD, Surampalli RY (2010) SSPRSD using a filamentous fungal strain Penicillium expansum BS30 isolated from wastewater sludge. J Environ Eng 136:719-730

5. Cai MQ, Hu JQ, Wells G, Seo Y, Spinney R, Ho SH, Dionysiou DD, Su J, Xiao RY, Wei ZS (2018) Understanding mechanisms of synergy between acidification and ultrasound treatments for activated sludge dewatering: From bench to pilot-scale investigation. Environ Sci Technol 52:43134323

6. Chen Y, Yang H, Gu G (2001) Effect of acid and surfactant treatment on activated sludge dewatering and settling. Water Res 35:2615-2620

7. Christensen ML, Keiding K, Nielsen PH, Jørgensen MK (2015) Dewatering in biological wastewater treatment: A review. Water Res 82:14-24

8. Chroumpi T, Makela MR, de Vries RP (2020) Engineering of primary carbon metabolism in filamentous fungi. Biotechnol Adv 43:107551-107573

9. Fakhru'I-Razi A, Alam MZ, Idris A, Abd-Aziz S, Molla AH (2002) Filamentous fungi in Indah Water Konsortium (IWK) sewage treatment plant for biological treatment of domestic wastewater sludge. J Environ Sci Health 37:309-320 
10. Fakhru'l-Razi A, Molla AH (2007) Enhancement of bioseparation and dewaterability of domestic wastewater sludge by fungal treated dewatered sludge. J Hazard Mater 147:350-356

11. Faye MCAS, Zhang KK, Peng S, Zhang YR (2019) Sludge dewaterability: the variation of extracellular polymeric substances during sludge conditioning with two natural organic conditioners. J Environ Manage 251:109559-109568

12. Frølund B, Palmgren R, Keiding K, Nielsen PH (1996) Extraction of extracellular polymers from activated sludge using a cation exchange resin. Water Res 30:1749-1758

13. Guibaud G, Tixier N, Baudu M (2005) Hysteresis area, a rheological parameter used as a tool to assess the ability of filamentous sludge to settle. Process Biochem 40:2671-2676

14. He DQ, Wang LF, Jiang H, Yu HQ (2015) A Fenton-like process for the enhanced activated sludge dewatering. Chem Eng J 272:128-134

15. Jernejc K, Legiša M (2004) A drop of intracellular pH stimulates citric acid accumulation by some strains of Aspergillus niger. J Biotechnol 112:289-297

16. Kacprzak M, Neczaj E, Okoniewska E (2005) The comparative mycological analysis of wastewater and sewage sludges from selected wastewater treatment plants. Desalination 185:363-370

17. Khanal SK, Grewell D, Sung S, Van Leeuwen J (2007) Ultrasound applications in wastewater sludge pretreatment: a review. Crit Rev Environ Sci Technol 37:277-313

18. Li SM, Li RW, Tang YN, Chen G (2019) Microwave-induced heavy metal removal from dewatered biosolids for cost-effective composting. J Clean Prod 241:118342-118350

19. Li YY, Dong LM, Li YY, Zheng XY, Zhang C, Ding N (2019) Enhancement of biological fermented sludge dewaterability by inoculation of filamentous fungi Mucor circinelloides XY-Z and Penicillium oxalicum LY-1. Dry Technol 37:1678-1687

20. Liang JL, Zhang L, Ye MY, Guan ZJ, Huang JJ, Liu JY, Li L, Huang SS, Sun SY (2020) Evaluation of the dewaterability, heavy metal toxicity and phytotoxicity of sewage sludge in different advanced oxidation processes. J Clean Prod 265:121839-121848

21. Liu H, Yang S, Shi JS, Xu XY, Liu HB, Fu B (2016) Towards understanding the dewatering mechanism of sewage sludge improved by bioleaching processing. Sep Purif Technol 165:53-59

22. Liu H, Shi JS, Xu XY, Zhan XM, Fu B, Li YF (2017) Enhancement of sludge dewaterability with filamentous fungi Talaromyces flavus S1 by depletion of extracellular polymeric substances or mycelium entrapment. Bioresour Technol 245:977-983

23. Liu J, Yang Q, Wang DB, Li XM, Zhong Y, Li X, Deng YC, Wang LQ, Yi KX, Zeng GM (2016) Enhanced dewaterability of waste activated sludge by Fe(II)-activated peroxymonosulfate oxidation. Bioresour Technol 206:134-140

24. Low EW, Chase HA (1999) Reducing production of excess biomass during wastewater treatment. Water Res 33:1119-1132

25. Maqbool T, Cho J, Hur J (2019) Improved dewaterability of anaerobically digested sludge and compositional changes in extracellular polymeric substances by indigenous persulfate activation. 
Sci Total Environ 674:96-104

26. Molla AH, Fakhru'l-Razi A (2012) Mycoremediation-a prospective environmental friendly technique of bioseparation and dewatering of domestic wastewater sludge. Environ Sci Pollut Res 19:1612-1619

27. More TT, Yan S, Tyagi RD, Surampalli RY (2010) Potential use of filamentous fungi for wastewater sludge treatment. Bioresour Technol 101:7691-7700

28. Murugesan K, Selvam A, Wong JWC (2014) Flocculation and dewaterability of chemically enhanced primary treatment sludge by bioaugmentation with filamentous fungi. Bioresour Technol 168:198203

29. Neyens E, Baeyens J, Dewil R (2004) Advanced sludge treatment affects extracellular polymeric substances to improve activated sludge dewatering. J Hazard Mater 106:83-92

30. Sheng GP, Yu HQ, Li XY (2010) Extracellular polymeric substances (EPS) of microbial aggregates in biological wastewater treatment systems: a review. Biotechnol Adv 28:882-894

31. Wang HF, Hu H, Wang HJ, Zeng RJ (2019) Combined use of inorganic coagulants and cationic polyacrylamide for enhancing dewaterability of sewage sludge. J Clean Prod 211:387-395

32. Wang ZY, Zheng GY, Zhou LX (2015) Degradation of slime extracellular polymeric substances and inhibited sludge flocs destruction contribute to sludge dewaterability enhancement during fungal treatment of sludge using filamentous fungus Mucorsp. GY-1. Bioresour Technol 192:514-521

33. Wei LL, Xia XH, Zhu FY, Li QY, Xue M, Li JJ, Sun B, Jiang JQ, Zhao QL (2020) Dewatering efficiency of sewage sludge during $\mathrm{Fe}^{2+}$-activated persulfate oxidation: Effect of hydrophobic/hydrophilic properties of sludge EPS. Water Res 181:115903-115914

34. Wu BR, Dai XH, Chai XL (2020) Critical review on dewatering of sewage sludge: Influential mechanism, conditioning technologies and implications to sludge re-utilizations. Water Res 180:115912-115929

35. Xiao K, Chen Y, Jiang X, Tyagi VK, Zhou Y (2016) Characterization of key organic compounds affecting sludge dewaterability during ultrasonication and acidification treatments. Water Res 105:470-478

36. Yu GH, He PJ, Shao LM, He PP (2008) Stratification structure of sludge flocs with implications to dewaterability. Environ Sci Technol 42:7944-7949

37. Zhang H, Yang JK, Yu WB, Luo S, Peng L, Shen XX, Shi YF, Zhang SN, Song J, Ye N, Li Y, Yang CZ, Liang $S$ (2014) Mechanism of red mud combined with Fenton's reagent in sewage sludge conditioning. Water Res 59:239-247

38. Zhang WJ, Cao BD, Wang DS, Ma T, Xia H, Yu DH (2016) Influence of wastewater sludge treatment using combined peroxyacetic acid oxidation and inorganic coagulants re-flocculation on characteristics of extracellular polymeric substances (EPS). Water Res 88:728-739

39. Zhang WJ, Xiao P, Liu YY, Xu SW, Xiao F, Wang DS, Chow Christopher WK (2014) Understanding the impact of chemical conditioning with inorganic polymer flocculants on soluble extracellular polymeric substances in relation to the sludge dewaterability. Sep Purif Technol 132:430-437 


\section{Tables}

\section{Table 1.}

Pearson's correlation between sludge SRF and sludge property parameters influencing dewaterability.

\begin{tabular}{llllllll}
\hline Parameters & $\mathrm{pH}$ & Zeta potential & $\mathrm{d}_{50}$ & Cell density & Protein & Polysaccharide & Slime EPS \\
\hline Sludge SRF & $0.776^{* *}$ & $0.929^{* *}$ & $0.591^{* *}$ & $0.405^{*}$ & $0.435^{*}$ & $0.645^{* *}$ & $0.538^{* *}$ \\
\hline
\end{tabular}

** Correlation is significant at the 0.01 probability level (2-tailed)

* Correlation is significant at the 0.05 probability level (2-tailed)

\section{Table 2.}

Statistical analysis by ANOVA.

\begin{tabular}{llllll}
\hline \multicolumn{7}{c}{ Parameter estimates } \\
\hline Variable & DF & Parameter estimate & Standard error & t value & Pr > at \\
Intercept & 1 & -19.93 & 85.759 & -0.232 & 0.819 \\
pH & 1 & 20.80 & 11.281 & 1.844 & 0.080 \\
Zeta potential & 1 & -10.70 & 1.373 & -7.790 & 0.001 \\
d $_{50}$ & 1 & -9.88 & 3.450 & -2.864 & $\mathbf{0 . 0 1 0}$ \\
Cell density & 1 & -0.08 & 0.448 & -0.177 & 0.861 \\
Protein & 1 & -4.30 & 2.009 & -2.137 & 0.040 \\
Polysaccharide & 1 & 0.81 & 4.536 & 0.179 & 0.860 \\
Slime EPS & 1 & 1.79 & 2.288 & 0.783 & 0.443 \\
\hline
\end{tabular}

\section{Figures}

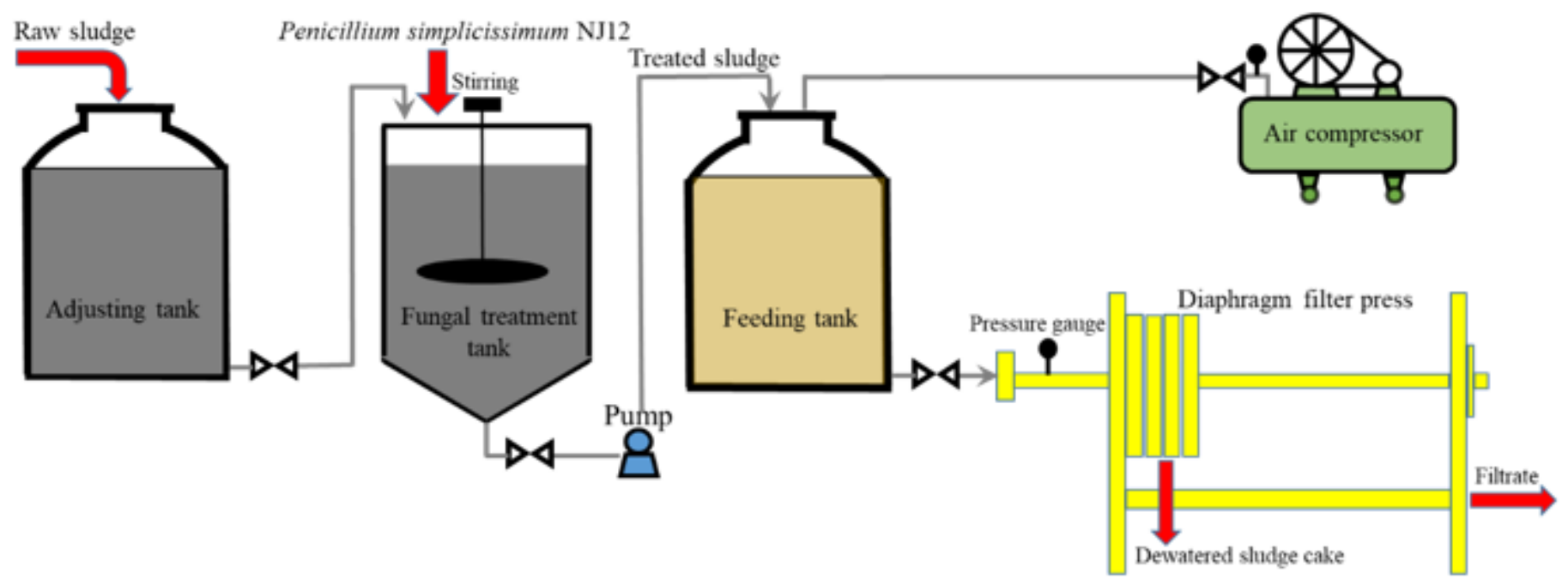


Pilot-scale setup of sludge dewatering system of fungal treatment with P. simplicissimum NJ12.
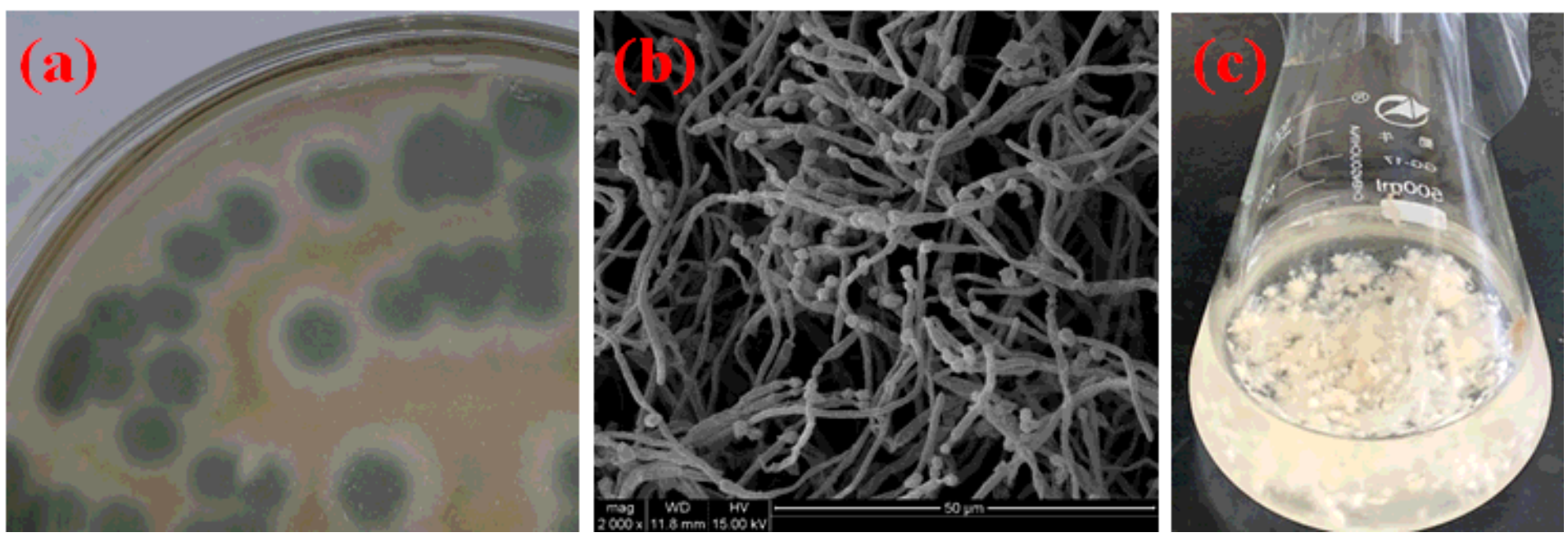

Figure 2

Morphology of the isolated strain P. simplicissimum NJ12 grown on PDA medium for 3 days (a), SEM image (b), and mycelial biomass grown in Czapek-Dox medium for 3 days (c)

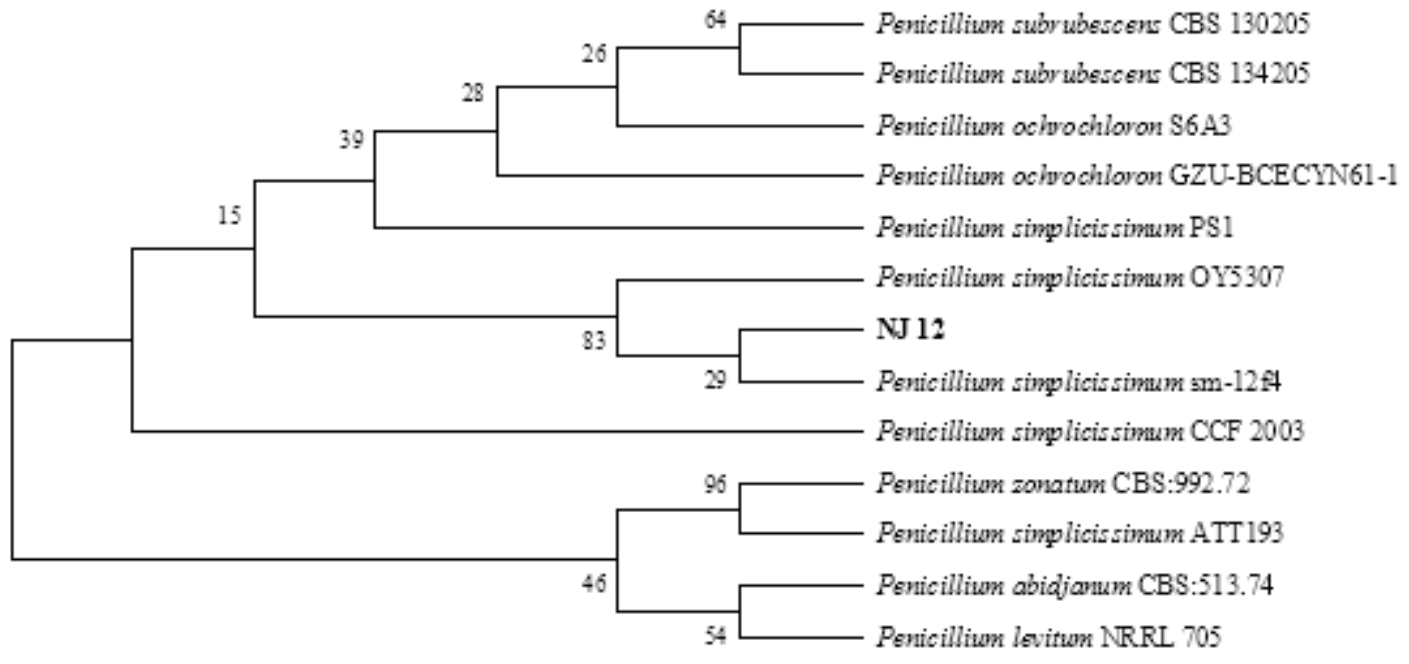

\section{Figure 3}

Phylogenetic tree based on the ITS rDNA sequence of the isolated strain P. simplicissimum NJ12. 

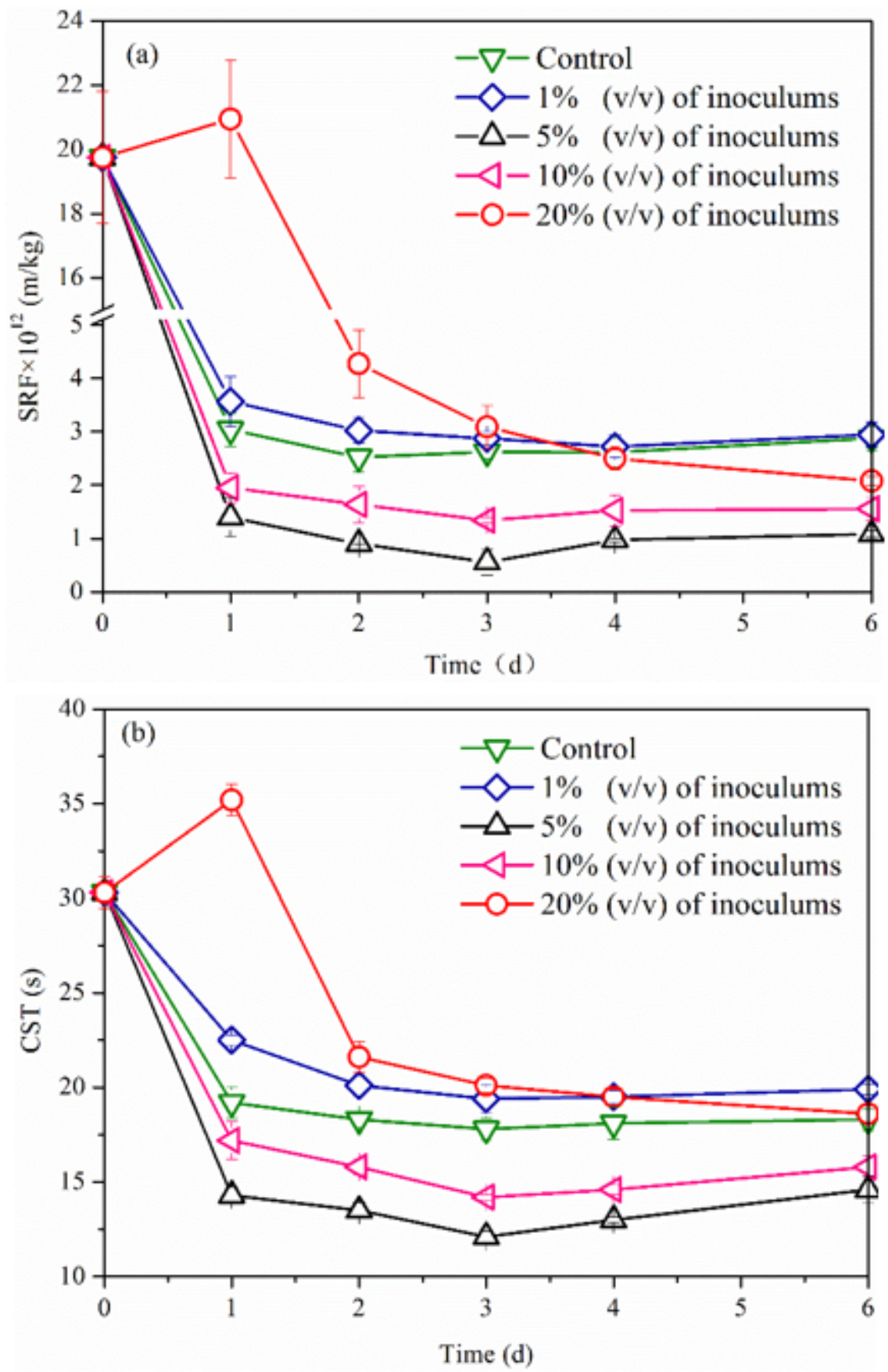

Figure 4

Changes in SRF (a) and CST (b) during fungal treatment of sludge with P. simplicissimum NJ12 at four different volume fractions of: $1 \%, 5 \%, 10 \%$, and $20 \%$. 

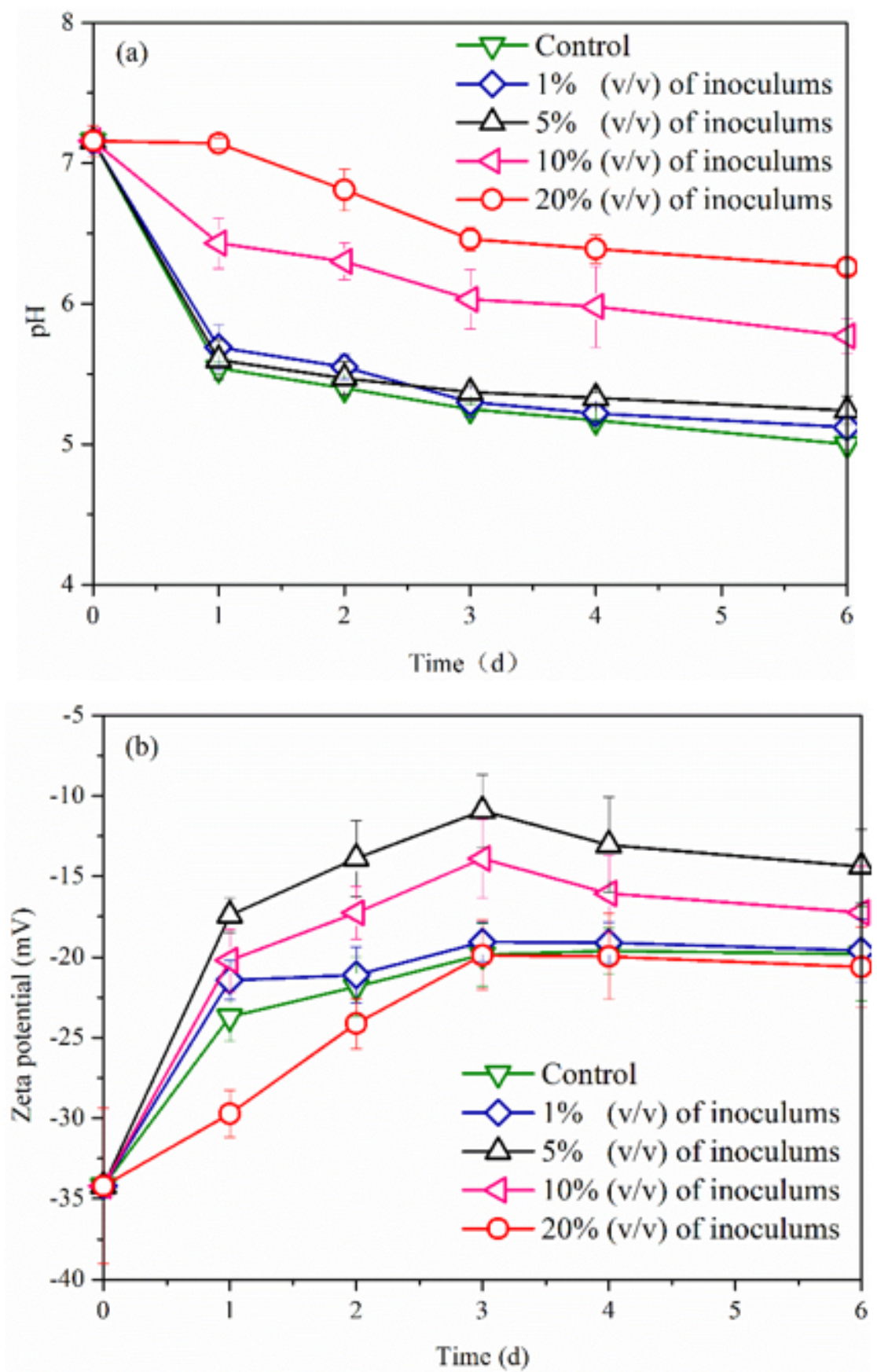

Figure 5

Changes in $\mathrm{pH}$ (a) and zeta potential (b) during fungal treatment of sludge with P. simplicissimum NJ12 at four different volume fractions of: $1 \%, 5 \%, 10 \%$, and $20 \%$. 

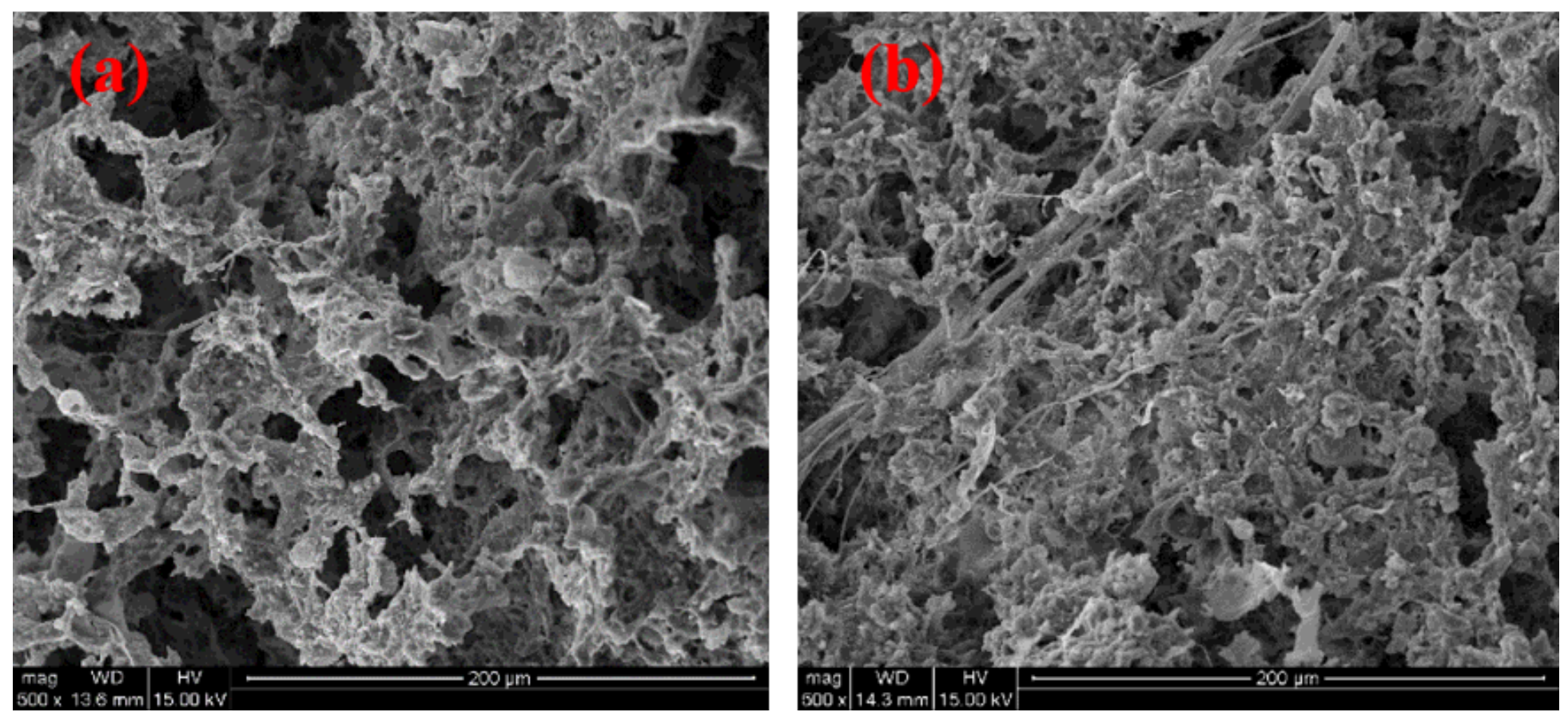

\section{Figure 6}

SEM images of raw sludge (a) and fungal-treated sludge (b) at the condition of a volume fraction of $5 \%$ of P. simplicissimum NJ12 inoculum and 3 days incubation. 


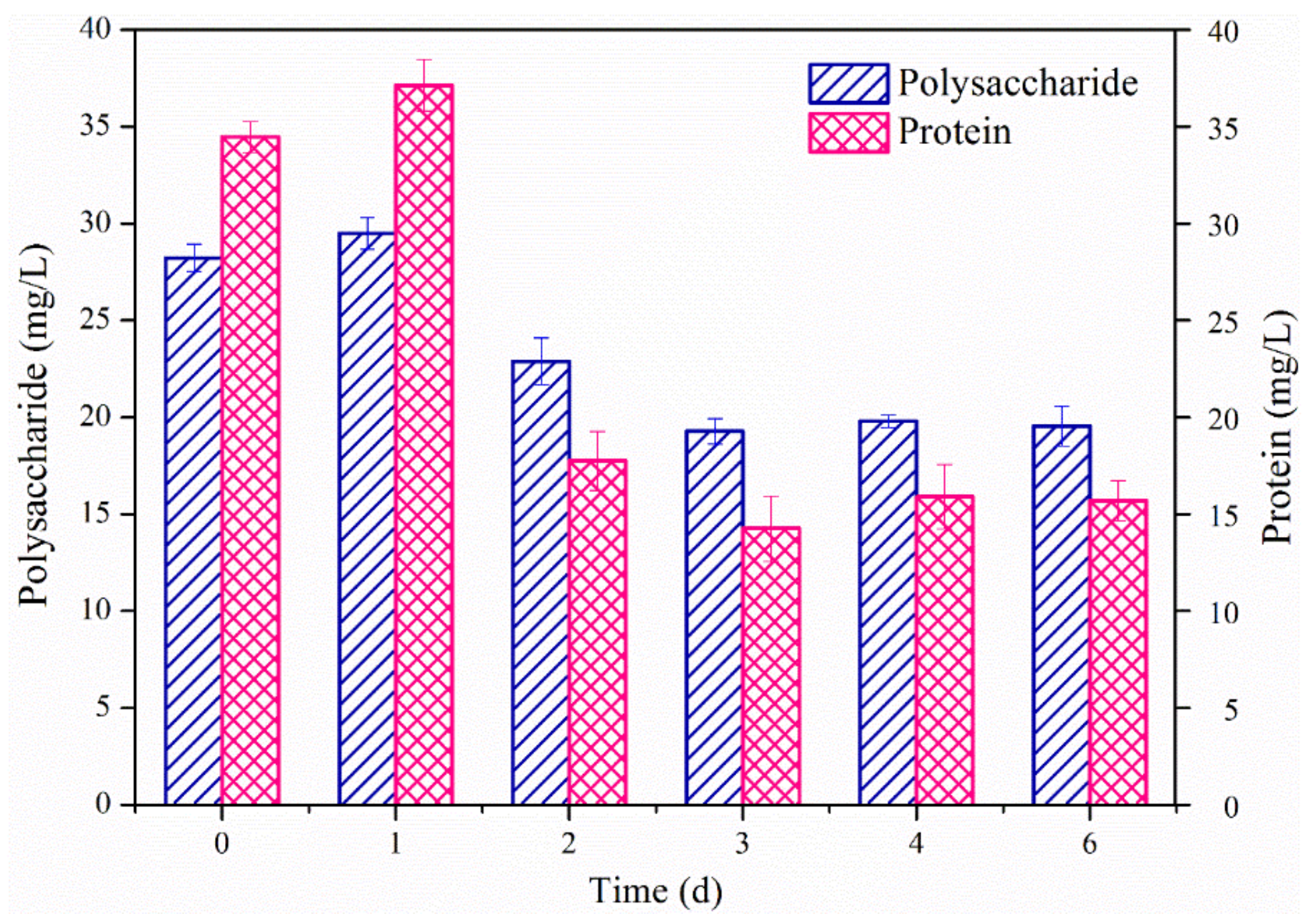

Figure 7

Changes in slime EPS components and contents during fungal treatment of sludge with P. simplicissimum NJ12 at a volume fraction of $5 \%$ of the inoculum. 


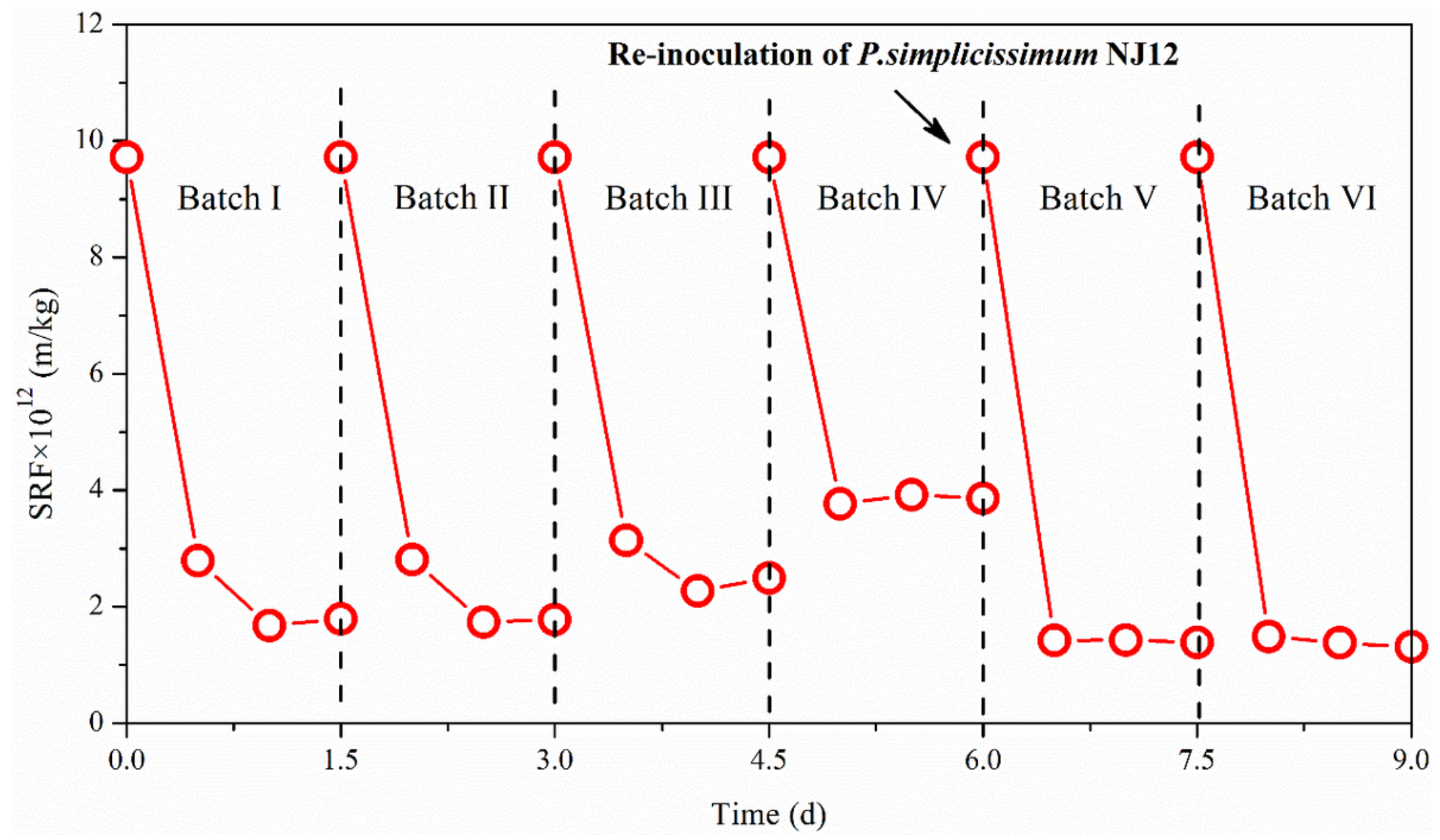

Figure 8

Changes in sludge SRF during pilot-scale consecutive multi-batch fungal treatment with a sludge recycling rate of 1:2 (Vbiotreated sludge/Vtotal sludge).

\section{Supplementary Files}

This is a list of supplementary files associated with this preprint. Click to download.

- Supplementarymaterial.docx 